Education Today

Elsevier Editorial System(tm) for Nurse

Manuscript Draft

Manuscript Number: NET-D-16-00357

Title: The integration and evaluation of a social-media facilitated journal club to enhance the student learning experience of evidence based practice

Article Type: Research Paper

Section/Category: Research articles

Keywords: Critical thinking; curriculum planning; evidence-based practice; nurse education; social media

Corresponding Author: Dr. Caleb Ferguson, RN, PhD, MHlth, BScN, MACN

Corresponding Author's Institution: University of Technology Sydney

First Author: Caleb Ferguson, RN, PhD, MHlth, BScN, MACN

Order of Authors: Caleb Ferguson, RN, PhD, MHlth, BSCN, MACN; Michelle Digiacomo, BA, MHsc, PhD; Leila Gholizadeh, RN, PhD; Leila E Ferguson, BA (Hons), BA, MA, PhD; Louise D Hickman, RN, MPH, PhD

Manuscript Region of Origin: AUSTRALIA

Abstract: Introduction

Nurses are required to interpret and apply knowledge so communities will receive care based on best available evidence, as opposed to care that is simply based on tradition or authority. Fostering nursing students' critical appraisal skills will assist in their capacity to engage with, interpret and use best evidence. Journal clubs are frequently used approach to engage learners with research and develop critical appraisal skills. Given new flipped and blended approaches to teaching and learning there is need to rejuvenate how research is utilised and integrated within journal clubs to maximise engagement and translation of evidence.

Purpose

This paper provides a case study of a single site Australian university experience of transitioning a traditional physical journal club, to a social media-facilitated club within a postgraduate health subject to stimulate and facilitate engagement with the chosen manuscripts.

Data sources

This case study is based on our own experiences, supported by literature and includes qualitative comments obtained via student feedback surveys during November 2015 .

Design

Case study

Implications for Nursing and Conclusion 
Social media-facilitated journal clubs offer an efficient way to continue developing critical appraisal skills in nursing students. The integration of a social media-facilitated journal clubs increased student attention, engagement with presented activities and overall student satisfaction within this evidence based practice subject. Future rigorously-designed, large-scale studies are required to evaluate the impact of online journal clubs on the uptake of evidence based practice, including those resulting in improved patient outcomes. 
$24^{\text {th }}$ April 2016

Graduate School of Health

University of Technology, Sydney

PO Box 123

BROADWAY NSW, Australia. 2007

Telephone: +61295147235

Editorial Team

Nurse Education Today

Dear Editor in Chief,

Re: The integration and evaluation of a social-media facilitated journal club to enhance the student learning experience of evidence based practice

My co-authors and I hope you find this discussion paper titled "The integration and evaluation of a social-media facilitated journal club to enhance the student learning experience of evidence based practice" of potential interest to the readers of the Nurse Education Today.

Journal clubs are vital in nursing education and practice; however there is a need for rejuvenation and strengthening of these initiatives. This paper highlights that social media offers a unique opportunity for students and clinicians to participate in online based journal clubs, regardless of geographic location. Further, that Twitter based journal clubs are low cost, and efficient means of developing critical appraisal skills of research studies. Overall, we found increased student attention, interaction and experience in this activity.

All authors contributed to this current manuscript. All authors meet the criteria for authorship and have given their final approval of the manuscript submitted to Nurse Education Today. No author has a conflict of interest related to this manuscript. This manuscript is not currently submitted to any other journal for consideration.

I look forward to receiving your reply to our submission.

Yours sincerely,

Dr Caleb Ferguson RN, PhD

Chancellors Postdoctoral Research Fellow

Graduate School of Health

University of Technology Sydney, Australia

Corresponding Author 


\section{The integration and evaluation of a social-media facilitated journal club to enhance the student learning experience of evidence-based practice: a case study.}

Nurse Education Today

1) Dr. Caleb FERGUSON RN, BScN, MHIth, PhD, UTS Chancellors Postdoctoral Research Fellow, Graduate School of Health, University of Technology Sydney.

2) Dr. Michelle DIGIACOMO BA, MHSc, PhD, Senior Research Fellow, Centre for Cardiovascular \& Chronic Care, Faculty of Health, University of Technology Sydney.

3) Dr. Leila GHOLIZADEH RN, PhD, Lecturer, Faculty of Health, University of Technology Sydney.

4) Dr. Leila E. FERGUSON BA (Hons), BA, MA, PhD, Postdoctoral Research Fellow, Department of Education, Faculty of Educational Sciences, University of Oslo.

5) Associate Professor Louise D. HICKMAN RN, MPH, PhD, Associate Professor \& Director of Postgraduate Nursing Studies, Faculty of Health, University of Technology Sydney.

\section{Corresponding Author:}

Dr. Caleb Ferguson RN, PhD

UTS Chancellors Postdoctoral Research Fellow,

Graduate School of Health, University of Technology Sydney.

PO Box 123, Jones St, Ultimo, Sydney, NSW, 2007 Australia.

Tel +61 295147235

Email: Caleb.Ferguson@uts.edu.au

Twitter: @calebferg; @mdigiac3; @drlouisehickman; @uts_health

Conflict of Interest Statement: The authors declare no conflicts of interest, and explicitly no financial interest in Twitter.

Funding statement: This study received funding through a University of Technology Sydney, Australia: 2015 Vice Chancellors Teaching \& Learning Grant.

Final Word Count: 4305 


\section{Summary Statement}

To enhance knowledge translation capacity of nurses, the nursing profession needs to continue to develop and evaluate innovative models that better support clinical educators and academics to stimulate and facilitate engagement with the research and evidence. Journal clubs are vital in nursing education and practice; there is a need for rejuvenation and strengthening of these initiatives.

Social media offers a unique opportunity for students and clinicians to participate in online based journal clubs, regardless of geographic location. Twitter based journal clubs are low cost, and efficient means of developing critical appraisal skills of research studies.

Overall, student attention, interaction and experience were highly ranked in this activity. Future evaluation of the impact of Twitter journal clubs on the uptake of evidence based practice is warranted. 


\section{Abstract}

\section{Introduction}

Nurses are required to interpret and apply knowledge so communities will receive care based on best available evidence, as opposed to care that is simply based on tradition or authority. Fostering nursing students' critical appraisal skills will assist in their capacity to engage with, interpret and use best evidence. Journal clubs are frequently used approach to engage learners with research and develop critical appraisal skills. Given new flipped and blended approaches to teaching and learning there is need to rejuvenate how research is utilised and integrated within journal clubs to maximise engagement and translation of evidence.

\section{Purpose}

This paper provides a case study of a single site Australian university experience of transitioning a traditional physical journal club, to a social media-facilitated club within a postgraduate health subject to stimulate and facilitate engagement with the chosen manuscripts.

\section{Data Sources}

This case study is based on our own experiences, supported by literature and includes qualitative comments obtained via student feedback surveys during November 2015.

\section{Design}

Case Study

\section{Implications for Nursing and Conclusion}

Social media-facilitated journal clubs offer an efficient way to continue developing critical appraisal skills in nursing students. The integration of a social media-facilitated journal clubs increased student attention, engagement with presented activities and overall student satisfaction within this evidence based practice subject. Future rigorously-designed, large-scale studies are required to evaluate the impact of online journal clubs on the uptake of evidence based practice, including those resulting in improved patient outcomes.

Keywords; Critical thinking; curriculum planning; evidence-based practice; nurse education; social media 


\section{Introduction}

Nurses are required to interpret and apply knowledge to provide care to patients based on best available evidence, as opposed to care that is simply based on tradition or authority(Greenhalgh, 2010). A key challenge for the higher education sector and the continuing education of health care professionals is the provision of skills, knowledge and values that promote critical and responsible consumption, adaption and application of research evidence, policies and guidelines to practice. Documented barriers to optimising the use of evidence in clinical practice include those related to cultural context, resources and economics, and workforce (Greenhalgh, 2010). These include clinicians not being prepared or adequately skilled to access relevant high quality evidence related to clinical need in a timely fashion, lacking skills in the quality appraisal of different types of literature, and lacking understanding and appreciation of the evidence-based practice movement in modern day healthcare (Hoffman et al., 2010, Cullum et al., 2008, Greenhalgh, 2010). Negative stereotypes and general disinterest have been noted in relation to educational strategies that have objectives aimed at evidence implementation (Tetley and Glover, 1999). Similarly, academics also report negative attitudes, anxiety and distress related to teaching these subjects (Burrows and Baillie, 1997, Perkins, 1992). Reasons for both students' and academics' dissatisfaction with these core subjects are complex and multifaceted, although current teaching methods have been identified as a major contributing factor (Halcomb and Peters, 2009). Adopting different teaching methods such as blended and flipped approaches; reflection and the integration of online activities are alternative strategies that may potentially increase students' knowledge and translation of evidence (Halcomb and Peters, 2009). Blended and flipped approaches, may include where students are taught through a combination of traditional instruction (face to face) as well as being required to engage in activities out of the class, generally using a range of technological resources and effectively freeing class time for more student centred activities (O'Flaherty and Phillips, 2015). There is great focus on embedding social media validated tools for learning in university, driven by general interest and the widespread use.

This paper discusses a novel approach to engage postgraduate nursing students in developing critical appraisal skills, such as paying attention to and evaluating source information, methods, and interpretation of results, in evidence-based practice (Bowles et al., 2013).

If the knowledge translation capacity of postgraduate students is to be enhanced it is essential that as a professional nursing continues to develop and evaluate innovative models that better support academics responsible for provision of these core subjects. Evidence-based practice is a systematic empirical approach that has evolved out of recognition that the profession's body of knowledge is constantly changing. Evidence suggesting best methods of practice today may change in the future as more knowledge is produced. The task of staying abreast, although challenging, is facilitated when one has the ability to locate and critically appraise evidence, and decide on whether to incorporate it into every day practice. Having the ability to critically evaluate an evolving body of evidence and then translate or integrate this knowledge into practice is a complex process, yet vital to improving outcomes, as it may eliminate ineffective or harmful practices. It requires professionals to actively seek out new, more effective scientifically proven practices and to discard practices shown to be ineffective or harmful (Greenhalgh, 2010).

Bridging the divide between evidence and practice is important, given the aging population, innovations in treatment, and global fiscal constraints. Evidence-based nursing is much more than 
simply reading research articles (Greenhalgh, 2010). Nurses are required to engage with research, gain skills in appraisal of research studies, and develop critical literacy habits, which journal clubs have previously achieved. Journal clubs are a low cost and pragmatic method making clinicians more aware of research and able to meet the requirements of regulatory authorities to deliver evidence based care (Hunt and Topham, 2002). Further, registered nurses have a responsibility and duty of care to remain abreast with new evidence to inform best practice and provide evidencebased care (Australian Health Practitioner Regulation Agency (AHPRA), 2010). Therefore, developing critical literacy habits and appraisal skills is fundamental to the provision of evidence based care to patients. Within the contemporary higher education setting, universities are moving towards flipped and blended pedagogical approaches to teaching and learning (Hung and Chou, 2015, O'Flaherty and Phillips, 2015). Flipped classrooms in nurse programmes can have favourable academic outcomes and increased student satisfaction (Betihavas et al.). As part of a university-wide flipped learning strategy, the case study discussed within this paper aimed to 'flip' a classroom-based journal club to an online format for postgraduate nursing students, enrolled in a Masters of Advanced Nursing course.

\section{Purpose}

1) This paper aims to present a case study sharing the experience of academics in developing and embedding of a social media-facilitated journal club within a postgraduate health subject.

2) The aim of the social media based journal club was to improve critical appraisal skills of research studies in postgraduate nursing students. This was achieved through an augmented learning experience combining both face-to-face and digital learning approaches.

The conduct of this study was approved by the Human Research \& Ethics Committee of the XXXXX

\section{Data Sources}

This case study is based on our own experiences, supported by literature and includes qualitative comments obtained via student feedback surveys during November 2015. 


\section{Background}

\section{Traditional journal club components}

There are vast array of models of journal clubs, many with similar conceptual underpinning principles. Some use standardised critical appraisal tools, and the usual format may include approx. 1-hour timeframe, on a once per month basis. The following 13 components are proposed by Honey \& Baker (2011) as essential features to successful journal clubs (Honey and Baker, 2011). They include: 1) using a stated working definition, clearly stated focus and ground rules; 2 ) operating with management approval; 3) using a critical appraisal tool or reading guide; 4) to be question driven where questions are mainly generated from participants; 5) voluntary attendance; 6) situated within a work-based venue during regular work hours; 7) multidisciplinary; 8) limit participant numbers; 9) take place once a month for 1 hour during; 10) papers are shared prior to meeting; 11) to include participation of a clinical librarian, statistician, or other consultant; 12) include triangulation of outcome measures of knowledge, skills, attitudes and behaviours; 13) offer continuing professional development (CPD) hours as incentives for participation.

\section{Online journal clubs}

Online journal clubs are not new. Many specialties have been working with various approaches to online-based journal clubs since the advent of the Internet. Kuppersmith and colleagues reported over 15 years ago on an email-based distribution system mode of journal clubbing (Kuppersmith et al., 1997). They report the main advantages as removing geographic boundaries and overcoming time restrictions. A key advantage of this system in 1997 was that anyone with internet access could participate via an email distribution journal club channel. Approximately 15 years later, in 2012, the WeNurses Twitter community was born. WeNurses is a Twitter-based discussion group for nurses that was launched in July 2012, by registered nurse, Teresa Chinn. Since this global Twitter nursing community has grown exponentially, and continues to host weekly Twitterchats on different topics such as handover, infection prevention, communication and compassion (Moorley and Chinn).

Many other disciplines and specialties have leveraged Twitter as a platform to host Twitterchats amongst colleagues, and to chat and share scholarly discussion and critical evaluation of research studies (e.g. the Journal of General Internal Medicine and the International Urology Journal Club) (Mehta and Flickinger, 2014, Thangasamy et al., 2014). The International Urology Journal Club (\#urojc) has been one of the more successful on going chats, attracting 189 unique users from 19 countries and 6 continents over 12 months in 2012-2013. These data demonstrate the success such initiatives have, which would have not been as practical or achievable pre-Twitter. There remains scope to qualitatively evaluate the experiences of clinician-users, and patient care and outcomes as a result of participation in such continuing professional development activities. 


\section{Case Study: Re-designing evidenced based practice into a contemporary subject}

\section{Setting \& Participants}

Context: The case study presented within this discussion paper took place within the context of an inter-disciplinary postgraduate subject, offered in both Autumn and Spring semesters. The evidence based practice subject, offered across six different Masters Courses including; 1) Masters of Advanced Nursing; 2) Masters of Primary Healthcare; 3) Masters of Public Health; 4) Masters of Health Services Management; 5) Masters of Health Services Management and Planning; and 6) Masters of Health Policy. The student cohort is diverse with clinical nurses, nurse practitioner students, health planners and service managers, public health practitioners, and primary healthcare practitioners, including both international and domestic students, from countries including Nepal, India, Iran, and Saudi Arabia.

There was need to consider subject-redesign in view of previous student feedback, and in keeping with a new university-wide teaching and learning strategy to 'flipped learning'. Underpinning factors for subject re-design also included increasing student enrolments and related programming logistics, physical space restrictions, and resourcing. Prior to flipping the subject, students were taught primarily by didactic lectures (PowerPoint lectures), and journal club style workshops in large groups (classes of 30 students) by a skilled facilitator. Teachers and students used critical appraisal tools (http://www.casp-uk.net/) to guide critical thinking and appraisal.

\section{Rational for change}

A primary driver that underpinned change was the need for curriculum renewal and to meet University compliance with new teaching and learning strategy on flipped learning. The following student and teacher feedback was provided on previous iterations of in-class journal clubs reinforcing the need for change in delivery of content on appraising empirical journal articles:

1) Students found critical appraisal of literature boring and dry;

2) Students identified a disconnect between appraisal of literature and clinical practice;

3) Teaching critical appraisal skills of empirical research papers was challenging, particularly in keeping students engaged with concepts of study design, methodology and analysis when they had limited previous experience with these topics;

4) There was need to optimise class time ( $3 \times$ full day workshops, once per month for 3 month of semester).

\section{What is 'flipped learning'?}

A flipped approach to the classroom may assist to provide student-centered learning (Betihavas et al.). Willey \& Gardner (2013) outline:

"the requirement for flipped learning is that didactic transmission-based lectures are at least in part replaced with out of class tasks allowing class time for participative learning activities" ... "Flipped activities should preferably require students to engage in dialogue and include assessment (typically formative) to allow students to evaluate their understanding or progress." (Willey and Gardner, 2013). 
A flipped classroom typically reverses traditional teaching approaches. In a flipped model, students are introduced to concepts and new materials prior to the class, normally in the form of readings, online videos, podcasts, or other online materials. Class time is then utilized to undertake more complex work, such as problem solving, collaborative group work, or participatory activities (Betihavas et al., O'Flaherty and Phillips, 2015).

\section{The 'flipped model' to a journal club}

Table 1: A flipped model of journal club

INSERT TABLE 1 HERE

\section{Alignment with the university model of learning}

\section{Table 2: Alignment with the university model of learning}

\section{INSERT TABLE 2 HERE}

The case study provided is germane to the university model of learning (as detailed in Table 2). The Twitter Journal Club provides research-inspired and academically rigorous learning, integrates exposure to professional practice via tweets, encourages engagement, employs cutting-edge technology, and stimulates life-long learning . This method of conducting an online Twitter based journal club, is evidence based and has been previously trialled in other specialties with positive outcomes (Thangasamy et al., 2014). Nurses have a professional responsibility to be able to read papers, interpret findings, scrutinise study design and strengths and limitations of studies, and apply relevant findings to practice (Greenhalgh, 2010). Participation in a Twitter based chat exposes participants to a globally connected network of professional practitioners; engagement with this network may be beneficial in making global connections or establishing international relationships. Twitter is not 'cutting-edge technology', however its flexibility and adaptability mean that it is a highly useful tool in higher education. Evaluating this platform in a variety of nursing education settings is important prior to embedding into curriculum. Finally, there is a growing body of evidence on how Twitter can be an advantageous tool in developing nursing leadership, and for continuing professional development. There is undoubtedly potential for nurses to capitalise on the value of Twitter to meet the needs of regulatory agencies for revalidation, and for keeping abreast with the latest in evidence based practice (Moorley and Chinn, 2015, Moorley and Chinn, 2016). 


\section{Positive attributes of a social media facilitated journal club model.}

From our experience we were able to highlight a number of positive attributes to a social media facilitated journal club model. These include; 1 ) providing an authentic experience; 2) adopting a novel approach in teaching and learning; 3) encouraging student-student interaction and collaboration; 4) upskilling students with digital skills; 5) teacher role modelling of e-professionalism; and 6) developing students critical thinking and succinct writing skills.

1) Authentic experience; students are required to read and critically appraise research papers in real practice as Registered Nurses, therefore this activity provides an authentic experience for the student.

2) Novel approach; traditionally this subject can be 'dry' to students, and lacking in student engagement and satisfaction with content and student experience. This novel approach to the learning activity provided students the opportunity to interact with new technology and peers in a real-time, public forum.

3) Student-student interaction and collaboration; this activity encouraged student to student interaction in a digital environment. Whilst not fully achieved, having a skilled facilitator may encourage stronger student-student interaction. Reading and engaging with other students responses to gain understanding of concepts is an important aspect of this activity.

4) Up-skilling students with digital skills; students were required to be technologically savvy and competent in tweeting to undertake this activity. Most students found this an easy aspect of the activity, however having additional human resources to assist students with this aspect of the activity was important. It is vital that the nursing workforce is digitally competent.

5) Role modelling e-professionalism; this activity encouraged responsible use of social media. The facilitator role modelled professional behaviour on social media. This may assist in developing e-professionalism of students when using social media, and reduce inappropriate behaviour.

6) Development of critical thinking and succinct writing skills; students were required to keep their tweet responses to a max of 140 characters (including hashtag in response). This was a challenge for a few students, and may help to develop succinct writing skills, or how to provide a concise response. 
The activity and student experience was evaluated via the University- wide Student Feedback Survey at the end of semester (conducted in November 2015); an open text comment section was available for students to provide feedback, which is presented in Table 3 and Figure 1 below.

\section{INSERT TABLE 3 AND FIGURE 1 HERE}

Table 3: Qualitative student feedback on Twitter Journal Club

Figure 1: Qualitative student feedback on Twitter Journal Club 
In summary, 34 of the 59 students undertaking Evidence Based Practice in Spring 2015 responded to the student feedback survey (response rate $=58 \%$ ). One hundred percent of students strongly agreed or agreed that; 1 ) the learning opportunities provided helped me meet the stated objective of this subject; 2) they made the most of my opportunities to learn in this subject; 3 ) they were satisfied with the quality of this subject; 4) that subject has developed their ability to think critically; 5) the subject's learning opportunities made them aware of research in the area of evidence based practice. Further, $97 \%$ of respondents strongly agreed or agreed that 1) the subject's learning opportunities motivated me to conduct further self-directed learning; 2) the subject provided practical learning activities to develop new skills and knowledge I may need in the workplace; 3) the subject developed their understanding of my intended profession and 4) they understand current knowledge, theories and practices related to this subject.

\section{Reflections of academic Twitter journal club facilitator}

After conducting the first Twitter Journal Club in-class, out-of-class sessions were also scheduled, and conducted twice during the semester with mixed participation. As academics developing and embedding this approach to teaching students critical appraisal skills, we would like to share some reflections, and points for consideration in implementing this activity in other schools or universities.

1) Firstly, there is need for strong guidance and structure to the activity, as a method of reducing risk of student misconduct, and to ensure high standards of e-professionalism in the public digital world. This can be achieved through the timely provision of adequate pre-activity resources and readings.

2) In terms of sustainability, there is scope to engage with consumers and wider general public in future sessions. As healthcare providers we are experiencing a paradigm shift towards shared decision making, there is need to upskill 'expert patients' on the critical appraisal of open access scientific findings. Similarly, there is opportunity to mix and include other cohorts, including undergraduate, or other clinical specialties, or disciplines. Multidisciplinary online journal clubs would be favourable. In the digital age, there remains scope to upskill the current workforce in digital abilities, mentoring of the existing workforce to be included in online journal clubs may offer a solution to upskilling nurses in this area.

3) With all innovations, this activity is not without risk. Managing risk, a public audience, and exposure across Twitter is important. With larger groups of students, there would be the possibility to trend on Twitter, and trending tends to attract headlines of newspapers. Hence managing issues of e-professionalism prior to undertaking the issue is vital. The optimal size of a TwitterChat is yet to be determined. From our experience, there were differences on the quality of interaction between cohorts of 60 and 10. Discussion tended to be less rapid and interactive with small groups, and at a slower pace. However, large groups of $100+$ may be complex and challenging to manage. Some students demonstrated 'lurking' behaviour, which is perfectly normal for a first chat; managing digital behaviour with students such as 'lurking' and 'trolling' requires a skilled moderator. Providing formative feedback to students via a public forum may be challenging, developing protocols for managing this offline is important. 
4) There is need for additional resourcing and support for students to tap into for on call technical support. Using new digital platforms for the novice again can be challenging, and it is important to have skilled technical support on hand and accessible to students and academics. There is also need to up skill and prepare existing academics with a new skills set, away from delivering didactic style lectures, and becoming skilled TwitterChat facilitators and moderators.

5) Lastly, we offer some reflections on the quality of online and offline participation and interaction. To date, after conducting 4 journal clubs, we tend to find interaction is primarily student-teacher, and teacher -student. There is need to develop and strengthen the quality of student-student interaction. We hypothesise that developing highly skilled moderation techniques may assist in improving this aspect of the sessions. During the 75 minutes of in-class activity, students were mostly quiet and fully engaged on task with strong attention to task. This is impressive, and we are keen to explore this further, however hypothesise this may be due to the novelty aspect of the activity.

\section{Implications for Nursing and Conclusion}

To enhance the knowledge translation capacity of nurses, it is essential that the nursing profession continues to develop and evaluate innovative models that better support clinical educators and academics to stimulate and facilitate engagement with the research and evidence. Journal clubs are an essential component of nurse education and practice; however there is need for rejuvenation and innovation of these initiatives. This case study outlines how to successfully implement a flipped model of a journal club in postgraduate health programmes. Summated in in some of the presented feedback, such Twitter based journal clubs are efficient in developing critical appraisal skills in nursing students. Overall, we observed increased student attention on task, increased student engagement with activity, and increased student experience and satisfaction with an evidence based practice subject. Future rigorously designed, large-scale studies are required that evaluate the impact of online journal clubs on the uptake of evidence based practice, including clinician and patient outcomes. 


\section{$\underline{\text { References }}$}

AUSTRALIAN HEALTH PRACTITIONER REGULATION AGENCY (AHPRA). 2010. Nursing and Midwifery Continuing Professional Development Registration Standard [Online]. Canberra. [Accessed 4th August 2014 2014].

BETIHAVAS, V., BRIDGMAN, H., KORNHABER, R. \& CROSS, M. The evidence for 'flipping out' : A systematic review of the flipped classroom in nursing education. Nurse Education Today.

BOWLES, P. F., MARENAH, K., RICKETTS, D. M. \& ROGERS, B. A. 2013. How to prepare for and present at a journal club. Br J Hosp Med (Lond), 74, C150-2.

BURROWS, D. E. \& BAILLIE, L. 1997. A strategy for teaching research to adult branch diploma students. Nurse Education Today, 17, 39-45.

CULLUM, N., CILISKA, D., HAYNES, R. \& MARKS, S. 2008. Evidence-based nursing: An introduction, Oxford, UK, Wiley-Blackwell.

GREENHALGH, T. 2010. How to read a paper: The basics of evidence-based medicine, Oxford, UK, Wiley-Blackwell.

HALCOMB, E. J. \& PETERS, K. 2009. Nursing student feedback on undergraduate research education: implications for teaching and learning. Contemporary Nurse: A Journal for the Australian Nursing Profession, 33, 59-68.

HOFFMAN, T., BENNETT, S. \& DEL MAR, C. 2010. Evidence based practice: across the health professions, Sydney, Elsevier.

HONEY, C. P. \& BAKER, J. A. 2011. Exploring the impact of journal clubs: A systematic review. Nurse Education Today, 31, 825-831.

HUNG, M.-L. \& CHOU, C. 2015. Students' perceptions of instructors' roles in blended and online learning environments: A comparative study. Computers \& Education, 81, 315-325.

HUNT, C. \& TOPHAM, L. 2002. Setting up a multidisciplinary journal club in learning disability. Br J Nurs, 11, 688-93.

KUPPERSMITH, R. B., STEWART, M. G., OHLMS, L. A. \& COKER, N. J. 1997. Use of an Internet-Based Journal Club. Otolaryngology -- Head and Neck Surgery, 116, 497-498.

MEHTA, N. M. M. S. \& FLICKINGER, T. M. D. M. P. H. 2014. The Times They Are A-Changin': Academia, Social Media and the JGIM Twitter Journal Club. Journal of General Internal Medicine, 29, 1317-8.

MOORLEY, C. \& CHINN, T. 2015. Using social media for continuous professional development. Journal of Advanced Nursing, 71, 713-717.

MOORLEY, C. \& CHINN, T. 2016. Developing nursing leadership in social media. Journal of Advanced Nursing, 72, 514-520.

MOORLEY, C. R. \& CHINN, T. Nursing and Twitter: Creating an online community using hashtags. Collegian, 21, 103-109.

O'FLAHERTY, J. \& PHILLIPS, C. 2015. The use of flipped classrooms in higher education: A scoping review. The Internet and Higher Education, 25, 85-95.

PERKINS, E. R. 1992. Teaching research to nurses: issues for tutor training. Nurse Education Today, $12,252-257$.

TETLEY, J. \& GLOVER, J. 1999. Use of experiential methods to teach research in a pre-registration nursing curriculum. Nurse Education Today, 19, 633-638.

THANGASAMY, I. A., LEVERIDGE, M., DAVIES, B. J., FINELLI, A., STORK, B. \& WOO, H. H. 2014. International Urology Journal Club via Twitter: 12-Month Experience. European Urology, 66, 112-117.

UNIVERSITY OF TECHNOLOGY SYDNEY. 2015. Learning Futures [Online]. Sydney. Available: http://www.uts.edu.au/about/faculty-health/what-we-do/learningfutures [Accessed 01/02/2016 2016].

WILLEY, K. \& GARDNER, A. Flipping your classroom without flipping out SEFI Annual Conference, 2013. 1-9. 
Table 1: A flipped model of journal club

\section{Underpinning pedagogical principles:}

- Active learning experiences remain focus of campus attendance

- Collaborative learning experiences both on-campus and online

- Significant opportunities for students to receive feedback

- Clear link between subject objectives, graduate attributes, student learning activities and assessment.

\section{Pre-Class:}

- Students are provided with readings and web-based resources, made available via a Blackboard web platform. Resources included: 1) how to set up a Twitter account; 2) guidance on social media from regulatory authorities and nursing organisations; 3 ) readings on e-professionalism; 4) useful links to WeNurses resources; 5) links to evidence based practice experts' Twitter feeds (including Professor Paul Glasziou and Professor Trisha Greenhaulgh) to review as role models.

- Students were provided with a journal article depicting a randomised control trial (RCT) and asked to read it with consideration of a provided critical appraisal tool ( CASP).

- Students were required to set up a Twitter account, and bring a fully charged mobile device to class.

- Academic set up included embedding a Twitter feed widget into Blackboard and registering a hashtag for the purposes of the session (XXXXX)

\section{In-Class:}

- An introduction to the activity was provided orally by the lecturer in class. Students were reminded of their obligations when using social media (and in keeping with regulatory authority professional practice standards). Students were reminded that this was an open public forum, where Tweets that were posted, were viewable to the general public. Students had the option not to participate, or to participate in pairs. Most students had access to their own smartphone or tablet device. Free wi-fi was provided within the university classroom for students. Ensuring a class culture of collegiality, and friendly atmosphere was important, alongside the briefing to students. Ensuring that technological help was on hand was important and that students felt trusting to share their responses in the digital world. Reinforcing the formative learning nature of the task was important.

- Individually, or in pairs, students were asked to log in to Twitter on their electronic device, and follow class hashtag (XXXXXX). Students were asked to introduce themselves, and generally respond with perceptions of the paper (limited to 140 character tweets).

- During the 60 minute session, the TweetChat Moderator/ Facilitator (lecturer) would disseminate $1 \times$ CASP question (12 in total). 1 CASP question was delivered approximately every 5 minutes via Twitter with the accompanying hashtag, in order to keep the appraisal moving. A total of 12 questions were delivered over the hour. Students would be required to answer each CASP question to the best of their ability, using the hashtag provided, and may choose to interact with other students or the lecturer by mentioning them in their tweet. This would encourage discussion amongst the lecturer and students.

- Students were not encouraged to discuss answers orally in class with peers or their lecturer, but rather to tweet to one and other with their responses.

- Two additional tech-proficient academics were on hand to assist with technical issues related to using Twitter and technology, however they were advised not to answer 'study type', or 'methodological type' questions. Rather, they were instructed to direct students to seek information from their peers or lecturer via Twitter.

- The TweetChat Moderator/ Facilitator (lecturer) tweeted from the front lectern in class. This 
role was quite intensive, as there were 60 students participating in the first in-class Twitter Journal Club. The Twitter hashtag and rolling conversation was projected on screen at the front of the class for students to review and contribute.

- A total of 14 questions were disseminated, (including $12 \times$ CASP questions, an introduction question and a closing feedback question). The chat lasted a total of 75 minutes.

\section{Post-Class:}

- Post Twitter-chat, a 'Storify' transcript was generated, and embedded in Blackboard, for students to refer to at a later date as a resource. Students who did not participate, had technical difficulties, or were absent from class could review this resource at a later stage.

- The activity and student experience was evaluated via the University Student Feedback Survey at the end of semester. No specific feedback question directly related to this activity. However, an open text comment section was available for students to provide feedback. 
Table 2: Alignment with the university model of learning

\begin{tabular}{|c|c|}
\hline University model of learning & Detail of alignment \\
\hline $\begin{array}{l}\text { - An integrated exposure to } \\
\text { professional practice } \\
\text { through dynamic and } \\
\text { multifaceted modes of } \\
\text { practice-oriented education }\end{array}$ & $\begin{array}{l}\text { - Twitter-journal club is an authentic, practice- } \\
\text { orientated activity. Registered nurses are required to } \\
\text { read papers and critically analyse these (make sense } \\
\text { of study findings and share with colleagues to inform } \\
\text { best practice). Further, they may be required to } \\
\text { make recommendations to other clinicians, patients } \\
\text { and caregivers based on the information reviewed. } \\
\text { Twitter allows students to connect with other } \\
\text { clinicians, to share ideas and experiences both } \\
\text { locally, and globally. The Twitter Nursing community } \\
\text { is growing, particularly due to the WeNurse } \\
\text { community. This community role models } \\
\text { professional use of social media, through its use as a } \\
\text { medium for continuing professional development. }\end{array}$ \\
\hline $\begin{array}{l}\text { - Learning which is research- } \\
\text { inspired and integrated, } \\
\text { providing academic rigor } \\
\text { with cutting edge } \\
\text { technology to equip } \\
\text { graduates for life-long } \\
\text { learning }\end{array}$ & $\begin{array}{l}\text { - This in-class and out-of-class activity required } \\
\text { students to become digitally literate, and } \\
\text { technologically savvy. Nurses are required to use } \\
\text { technology within their day-to-day practice, and a } \\
\text { wide variety of digital platforms. This activity assisted } \\
\text { in developing the graduate attribute of being } \\
\text { competent in providing technology enhanced care. }\end{array}$ \\
\hline
\end{tabular}


1. "It was fun/ challenging task. Must do it again! Thank you"

2. "Interesting and thought provoking activity!"

3. "Journal club was exceptional, innovative and nothing like I have ever experienced before"

4. "I found the session very exciting and interactive. I got to learn so many things. Thank you so much"

5. "I enjoyed the use of Twitter to discuss the research papers"

6. "I learned the skill of critical analysis and loved the interactive module of learning on twitter!! It was very different and a good experience to review articles through twitter journal club. My knowledge of EBP had increased tremendously due to combined efforts of all teachers"

7. "Twitter journal club was an innovative way of learning"

8. "I liked the fun laid back approach to learning"

9. "The most beautiful part of the subject was the twitter sessions. It was really helpful and interesting way to being interest in the subject. We enjoyed the classes as well as the sessions"

10. "The use of social media to facilitate classroom discussion was an interesting and novel approach which I found quite suiting the current evolving environment of health care"

11. "Continue twitter journal clubs.... Future students will surely enjoy it!"

12. "The use of social media made the subject for me"

13. "I was very happy with this subject. I did however not enjoy the twitter exercise my tweets would not load in time and it meant I was lagging behind"

14. "I was a Twitter user for years but apart from Bollywood and family friends, I never followed anyone... now I follow a lot of evidence-based practitioners and researchers and also get valuable updates. 


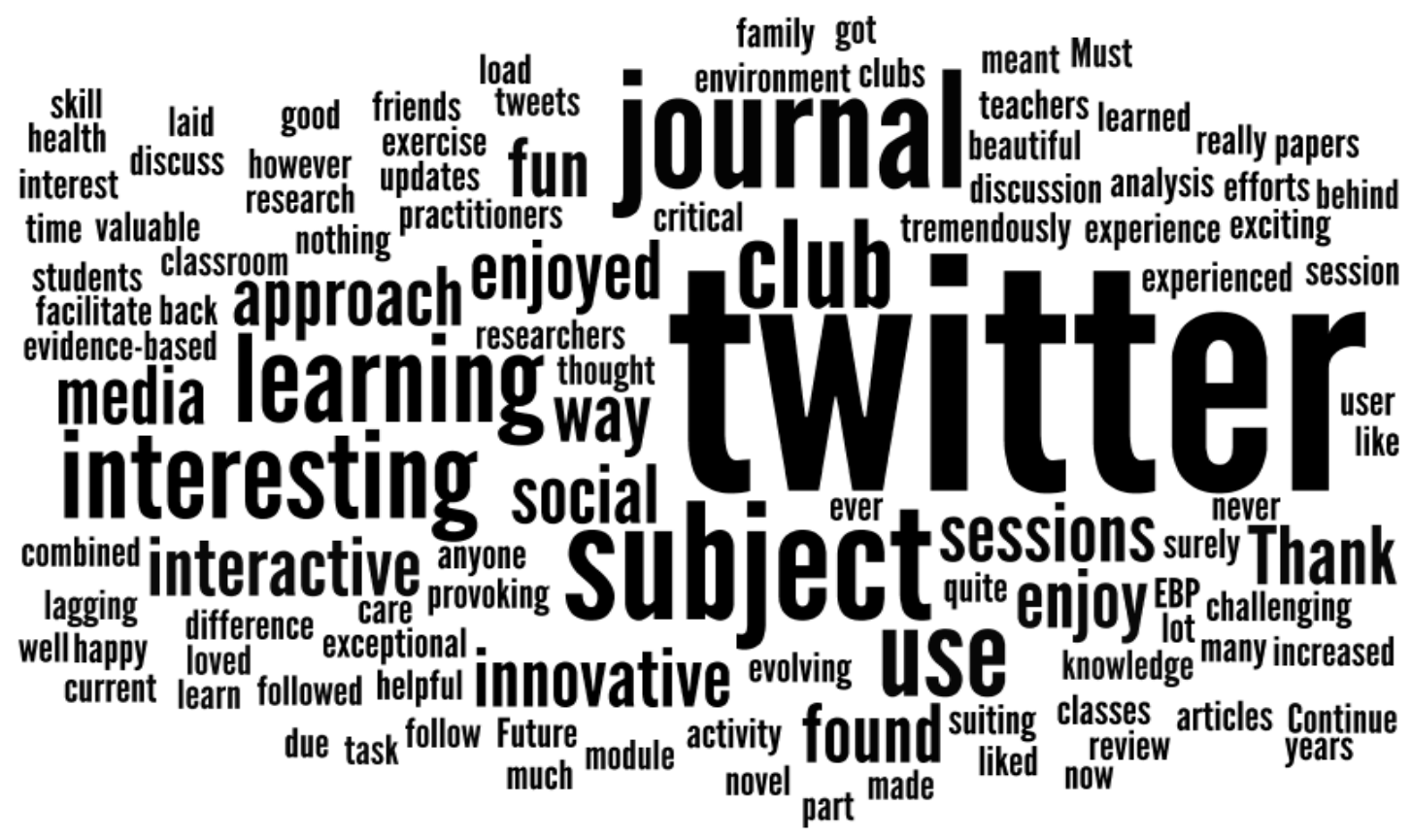

Figure 1: Qualitative student feedback on Twitter Journal Club 


\section{Research Highlights}

- Journal clubs are frequently used approach to engage learners with research and develop critical appraisal skills.

- Social media-facilitated journal clubs offer an efficient way to continue developing critical appraisal skills in nursing students.

- The integration of a social media-facilitated journal clubs increased student attention, engagement with presented activities and overall student satisfaction within this evidence based practice subject. 